\title{
PERSEPSI WISATAWAN TENTANG PARIWISATA OLAHRAGA DI MIRAH FANTASIA DESA LATENG KABUPATEN BANYUWANGI
}

\author{
Dimas Prayoga ${ }^{1}$, Wahjoedi ${ }^{2}$, I Ketut Semarayasa ${ }^{3}$ \\ 1,2,3Universitas Pendidikan Ganesha \\ Jurusan Pendidikan Olahraga \\ Program Studi Pendidikan Jasmani Kesehatan dan Rekreasi
}

Email : prayogadimas674@gmail. com¹, wahjoedi@undiksha.ac.id².ketut.semarayasa.ac.id ${ }^{3}$.

\begin{abstract}
ABSTRAK
Penelitian ini bertujuan untuk mengetahui persepsi wisatawan tentang pariwisata olahraga di Mirah Fantasia Desa Lateng Kabupaten Banyuwangi. Jenis penelitian adalah jenis penelitian deskriptif kuantitatif, dengan menggunakan metode survei dengan teknik pengambilan data observasi, kuisioner, dokumentasi. Populasi dalam penelitian ini adalah wisatawan yang berkunjung ke Mirah Fantasia dimana mereka yang telah menikmati pariwisata olahraga. Analisis data yang digunakan dalam penelitian ini yaitu deskriptif kuantitatif dengan persentase. Hasil penelitian ini menunjukan bahwa (1) sumber informasi dan tujuan berkunjung memiliki persentase cukup baik dengan $83 \%$. (2) Sarana dan prasarana pariwisata olahraga di Mirah Fantasia memiliki persentase cukup baik dengan 85\%. (3) Keunikan Mirah Fantasia memiliki persentase cukup baik dengan $86 \%$. (4) Jenis layanan wisata memiliki persentase cukup baik dengan $85 \%$. (5) Pengelolahan memiliki persentase cukup baik dengan $86 \%$. Kesimpulan bahwa (1) informasi mengenai Mirah Fantasia bisa didapatkan dengan mudah melalui media sosial dan media pemaparan. (2) Sebagai destinasi wisata rekreasi dengan keluarga, wisatawan memberikan persepsi yang positif terhadap pariwisata olahraga di Mirah Fantasia. (3) Potensi pariwisata olahraga yang ada di Mirah Fantasia juga membuat wisatawan memiliki persepsi yang positif untuk mendorong wisatawan meningkatkan minat berkunjung di Kabupaten Banyuwangi untuk mengunjungi Mirah Fantasia, dengan demikian peneliti menyarankan kepada wisatawan agar selalu menjaga kebersihan, dan kedepannya pengelola diharapkan terus berbenah agar menarik minat wisatawan untuk berkunjung, peneliti mengharapkan agar penelian ini dijadikan referensi untuk meneliti dalam ruang lingkup yang lebih luas.
\end{abstract}

Kata-kata kunci: Pariwisata Olahraga, Persepsi Wisatawan, Wahana

\begin{abstract}
This study aims to determine the perception of tourists about sports tourism in Mirah Fantasia, Lateng Village, Banyuwangi Regency. This type of research is descriptive quantitative research, using survey methods with observation data collection techniques, questionnaires, documentation. The population in this study were tourists who visited Mirah Fantasia where they have enjoyed sports tourism. The data analysis used in this research is descriptive quantitative with percentage. The results of this study indicate that (1) the source of information and the purpose of visiting has a good percentage of $83 \%$. (2) Facilities and infrastructure for sports tourism in Mirah Fantasia have a good percentage of $85 \%$. (3) The uniqueness of Mirah Fantasia has a good percentage of $86 \%$. (4) Type of tourism service has a fairly good percentage of $85 \%$. (5) Management has a fairly good percentage of $86 \%$. The conclusion is that (1) information about Mirah Fantasia can be obtained easily through social media and presentation media. (2) As a recreational tourism destination with families, tourists give a positive perception of sports tourism in Mirah Fantasia. (3) The potential for sports tourism in Mirah Fantasia also makes tourists have a positive perception to encourage tourists to increase their interest in visiting Banyuwangi Regency to visit Mirah Fantasia, thus the researcher suggests tourists to always maintain cleanliness, and in the future the manager is expected to continue to improve. attracting tourists to visit, researchers hope that this research will be used as a reference for researching in a wider scope.
\end{abstract}

Key words: sports tourism, perception of tourists, rides. 


\section{PENDAHULUAN}

Pariwisata telah ada pada zaman manusia dan semakin berkembang sampai sekarang. Menurut Warman \& Muljadi (2016: 7) Istilah pariwisata berasal dari dari dilaksanakan kegiatan wisata atau tour yaitu suatu aktivitas perubahan tempat tinggal sementara seseorang. Sedangkan menurut Eka dan Rai (2012:107) definisi pariwisata adalah salah satu dari industri baru yang mampu mengingkatkan pertumbuhan ekonomi dengan cepat dalam hal kesempatan kerja, pendapatan tarif hidup, dan dalam hal mengatifkan sektor produksi lain di dalam negara penerima wisatawan. Menurut Rai dan Eka (2012: 105) wisatawan adalah seseorang atau sekelompok orang yang melakukan suatu perjalanan wisata disebut dengan wisatawan (tourist), pariwisata olahraga merupakan paradigma baru dalam pengembangan pariwisata dan olahraga di Indonesia. Pariwisata olahraga merupakan perpaduan antara olahraga dan pariwisata yang saat ini berkembang pesat dan banyak peminatnya. Menurut Suratmin (2018: 30) olahraga dan pariwisata adalah gabungan aktivitas yang sangat meguntungkan jika digabungkan, banyak hal positif yang bisa didaapatkan dari kegiatan olahraga pariwisata. Pariwisata olahraga memberikan pengaruh yang sangat luar biasa dalam kesejahteraan masyarakat dan membantu perekonomian negara dan sisi lain untuk pembangunan sebuah pariwisata dibutuhkan bantuan pemerintah, masyarakat dan diarahkan untuk memacu peningkatan daya saing global dan pemasukan devisa dengaan upaya memajukan peningkatan daya saing globak dan pemasukan devisa dengan upaya memajukan pariwisata, antara lain melalui pariwisata olahraga yangberbasis rekreasi atau outboond.

Berdasarkan uraian di atas peneliti tertarik untuk melakukan penelitian dengan judul " Persepsi Wisatawan Tentang Pariwisata Olahraga di Mirah Fantasia Desa Lateng Kabupaten Banyuwangi.

\section{KAJIAN TEORI}

\section{Persepsi}

Persepsi merupaakan proses yang didahului oleh proses penginderaan yaitu merupakan proses diterimanya stimulus oleh individu melalui alat indera atau juga disebut proses sensoris. Namun proses itu tidak berhenti begitu saja, melainkan stimulus tersebut diteruskan dan proses selanjutnya merupakan proses persepsi. Stimulus yang diinderakan itu kemudian diorganisasikan dan diinterpretasikan sehingga individu menyadari dan mengerti apa yang diinderakan ini disebut proses persepsi, dalam Valentino (2015: 29) menyatakan bahwa persepsi adalah bagaimana seseorang membuat kesan pertama, prasangka apa yang mempengaruhi mereka dan jenis informasi apa yang kita pakai untuk sampai terhadap kesan tersebut dan bagaimana akuratnya kesan kita. Persepsi dipengaruhi oleh dua faktor yaitu factor dari dalam diri dan factor dari luar individu (walgito dalam widyasrama, 2013: 31)

\section{Wisatawan}

Wisatawan merupakan sekelempok orang yang berpegian ke luar tempat tinggalnya kurang lebih 24 jam untuk mencari kesenangan batin. Menurut Rai \& Eka (2012: 105). Menurut Utama (2018: 9) wisatawan adalah pengunjung sementara yang tinggal lebih dari 24 jam di suatu destinasi yang di kunjunginya dengan tujuan bersenang-senang (pleasure), bisnis, keluarga. Sedangkan pelancong adalah orang yang melakukan perjalanan kurang dari 24 jam di negara yang dikunjunginya termasuk penumpang kapal pesiar.

\section{Pariwisata}

Menurut Rai \& Eka (2012: 107). Pariwisata adalah salah satu dari industri baru yang mampu meningkatkan pertumbuhan ekonomi dengan cepat dalam hal kesempatan kerja, pendapatan, taraf hidup, dan dalam hal mengaktifkan sektor produksi lain dalam negara penerima wisatawan. Pariwisata adalah suatu perjalanan yang dilakukan untuk sementara waktu dari satu tempat ke tempat lain yang 
mempunyai objek dan daya tarik wisata yang dapat dinikmati sebagai suatu rekreasi atau hiburan mendapatkan kepuasan lahir dan batin. (Suratmin, 2018: 85). Pada UU RI No 10 tahun 2009 tentang Kepariwisataan, yang dimaksud dengan pariwisata adalah berbagai macam kegiatan wisata dan didukung berbagai fasilitas serta layanan yang disediakan oleh masyarakat, pengusaha, dan pemerintah daerah Berdasarkan pemaparan tersebut maka yang dimaksud dengan pariwisata dalam penelitian ini adalah suatu perjalanan yang dilakukan untuk sementara waktu dari satu tempat ke tempat lain yang mempunyai obyek dan daya tarik wisata untuk dapat dinikmati sebagai suatu rekreasi atau hiburan yang mendapatkan kepuasan lahir dan batin baik individu maupun dengan keluarga.

\section{Wahana Olahraga di Mirah Fantasia}

Mirah Fantasia ini mempuyai objek wahana yang berbasis pariwisata olaharaga, dimana wahana tersebut dapat menambah daya tarik wisatawan yang berkunjung. Wahana pariwisata olahraga yang ada adalah parasailing, banana boat, outbond, kano dan kolam renang.

\section{Fasilitas Pariwisata Olahraga}

Fasilitas pariwisata olahraga meliputi sarana dan prasarana dan di bagi menjadi dua, yaitu (a). Keamanan fasilitas pariwisata yakni sarana/prasarana yang ada di wahana wisata yang merupakan hal paling utama untuk diperhatikan. Sarana dan prasarana harus memenuhi standar keamanan dan dengan tim pelaksana yang berkompeten yaitu orang-orang yang telah mendapatkan pelatihan khusus tentang pengoperasian sarana/olaraga rekreasi. (b). Pengawasan terhadap keamanan fasilitas pariwisata olahraga yakni didalamnya dilakukan oleh Disparta yaitu bidang sarana/prasarana objek dan daya tarik wisata (ODTW) dengan dibantu oleh unit pelaksana teknik daerah (UPTD), dapat disimpulkan bahwa olahraga rekreasi adalah olahraga yang dilakukan secara kelompok maupun individu untuk tujuan rekreasi dan olahraga untuk menghilangkan stres denagn aktivitas gerak yang menyenangkan dan menyehatkan.

\section{METODE PENELITIAN}

Penelitian ini termasuk kedalam jenis penelitian deskriptif kuantitatif. Metode yang digunakan dalam pengumpulan data penelitian ini menggunakan metode survei dengan teknik pengambilan data observasi, kuisioner, dokumentasi. Populasi dalam penelitian ini adalah wisatawan yang berkunjung ke Mirah Fantasia dimana mereka yang telah menikmati pariwisata olahraga. Analisis data yang digunakan dalam penelitian ini yaitu deskriptif kuantitatif dengan persentase.

Berdasarkan pemaparan diatas pengumpulan data dalam penelitian ini menggunakan kuisioner, dimana kuisioner yang disebarkan terdapat 28 pernyataan. Jawaban wisatawan diklasifikasikan yaitu sangat setuju (SS), Setuju (S), Tidak Setuju (TS) dan Sangat Tidak Setuju.

Teknik analisis ini digunakan untuk mengolah data yang diperoleh melalui angket dalam bentuk Deskriptif persentase (Tegeh dan Jampel, 2017: 222). Menurut Tegeh dan Jampel, (2017: 222), rumus yang digunakan untuk menghitung persentase dari masing-masing subyek adalah:

$\sum$ (jawaban $\mathrm{x}$ bobot tiap pilihan) Persentase $==\times 100$ $\%$

Keterangan :

$$
\mathrm{n} \times \text { bobot tertinggi }
$$

$\Sigma=$ jumlah

$\mathrm{n} \quad=$ jumlah seluruh item angket

Selanjutnya, untuk menghitung persentase keseluruhan subjek menurut Tegeh dan Jampel, (2017: 223), yaitu menggunakan rumus:

Persentase $=(\mathrm{F}: \mathrm{N})$

Keterangan: $F=$ jumlah persentase keseluruhan subyek 
Tabel 1. Kisi-kisi instrumen

\begin{tabular}{ccc}
\hline Kk Kriteria Penilaian & $\begin{array}{c}\text { Sk Skor } \\
\text { Pernyataan } \\
\text { Positif }\end{array}$ & $\begin{array}{c}\text { Penyataan } \\
\text { Negatif }\end{array}$ \\
\hline SS : Sangat Setuju & 4 & 1 \\
ST : Setuju & 3 & 2 \\
TS : Tidak Setuju & 2 & 3 \\
STS : Sangat Tidak Setuju & 1 & 4 \\
\hline
\end{tabular}

\section{HASIL DAN PEMBAHASAN}

Desa Lateng terletak di kabupaten Banyuwangi, merupakan desa yang letaknya di desa karimun jawa. Desa ini memiliki hamparan topografi wilayah berupa persewahan dan perdesaan. Desa lateng juga memiliki wisata yang sangat terkenal yaitu Mirah Fantasia tempat wisata air yang sangat diminati pengunjung. Wahana yang terdapat di Mirah Fantasia kolam renang, banana boat, outbond, kano dan parasailing.

Dari hasil analisis data berdasarkan kuisioner yang sudah disebarkan dapat dijabarkan hasil sebagai berikut yaitu 1) Informasi Tentang Mirah Fantasia dan Tujuan Pengunjung; 2)Persepsi Sarana Prasarana Pariwisata Olahraga Mirah Fantasia; 3)Persepsi Wisatawan Tentang Keunikan Mirah Fantasia; 4)Jenis Layanan Wisata; dan 5)Persepsi Wisatawan Tentang Pengelolaan.

Hasil penelitian, dapat disimpulkan hasil data yang diperoleh sebagai berikut :

Tabel 2.

Sumber Informasi Tentang Mirah Fantasia dan Tujuan Pengunjung

\begin{tabular}{clcc}
\hline No & \multicolumn{1}{c}{ Sumber Informasi } & Persentase \% & Kategori \\
\hline 1 & Media Cetak & 81 & Baik \\
2 & Informasi lisan (keluarga, teman, & 85 & Baik \\
& saudara) & & \\
3 & Mencoba setiap wahana olahraga & 83 & Baik \\
4 & Rekreasi/liburan & 89 & Baik \\
5 & Olahraga & 80 & Baik \\
\hline \multicolumn{2}{c}{ Total Rata-rata } & $\mathbf{8 3 \%}$ & Baik \\
\hline
\end{tabular}

Tabel 3.

Persepsi Sarana dan Prasarana Pariwisata Olahraga Mirah Fantasia

\begin{tabular}{clcc}
\hline No & \multicolumn{1}{c}{ Sumber Informasi } & Persentase \% & Kategori \\
\hline 1 & $\begin{array}{l}\text { Jalan menuju ke Mirah Fantasia } \\
\text { terbilang mudah dan layak untuk } \\
\text { di lewati }\end{array}$ & 85 & Baik \\
2 & $\begin{array}{l}\text { Pengamanan di Mirah Fantasia } \\
\text { sangat bagus }\end{array}$ & 86 & Baik \\
3 & Transportasi dapat di tempuh & 88 & Baik \\
\hline
\end{tabular}




\begin{tabular}{|c|c|c|c|}
\hline & $\begin{array}{l}\text { dengan Kendaraan bermotor dan } \\
\text { mobil }\end{array}$ & & \\
\hline 4 & $\begin{array}{l}\text { Kamar mandi dalam kondisi } \\
\text { bersih }\end{array}$ & 83 & Baik \\
\hline 5 & $\begin{array}{l}\text { Locker merupakan sarana } \\
\text { penting untuk menyimpan } \\
\text { barang-barang pengunjung }\end{array}$ & 88 & Baik \\
\hline 6 & $\begin{array}{l}\text { Peralatan keamanan untuk setiap } \\
\text { wahana tersedia secara optimal }\end{array}$ & 84 & Baik \\
\hline 7 & $\begin{array}{l}\text { Kuliner di Mirah Fantasia } \\
\text { memenuhi } \\
\text { selera Wisatawan }\end{array}$ & 84 & Baik \\
\hline \multirow[t]{2}{*}{8} & $\begin{array}{l}\text { Gazebo di area Mirah Fantasia } \\
\text { membuat nyamana wisatawan }\end{array}$ & 85 & Baik \\
\hline & Total Rata-rata & $85 \%$ & Baik \\
\hline
\end{tabular}

Tabel 4.

Persepsi wisatawan tentang keunikan Mirah Fantasia

\begin{tabular}{clcc}
\hline No & \multicolumn{1}{c}{ Sumber Informasi } & Persentase \% & Kategori \\
\hline 1 & $\begin{array}{l}\text { Kolam renang menjadi wahana } \\
\text { paling favorit di Mirah Fantasia }\end{array}$ & 87 & Baik \\
\hline 2 & $\begin{array}{l}\text { Taman satwa menjadi wahana } \\
\text { paling favorit di Mirah Fantasia }\end{array}$ & 85 & Baik \\
\hline 3 & $\begin{array}{l}\text { Selain ada kolam renang di Mirah } \\
\text { Fantasia juga terdapat area } \\
\text { pantai, taman satwa dan outbond }\end{array}$ & 86 & Baik \\
\hline & Total Rata-rata & $\mathbf{8 6 \%}$ & Baik \\
\hline
\end{tabular}

Tabel 5.

Jenis layanan wisata Mirah Fantasia

\begin{tabular}{clcc}
\hline No & \multicolumn{1}{c}{ Sumber Informasi } & Persentase \% & Kategori \\
\hline 1 & $\begin{array}{l}\text { Berbagai jenis wahana wisata di } \\
\text { Mirah Fantasia membuat daya } \\
\text { Tarik wisatawan berkunjung }\end{array}$ & 87 & Baik \\
\hline 2 & $\begin{array}{l}\text { Outbond menjadi wahana yang } \\
\text { cukup menarik di coba }\end{array}$ & 87 & Baik \\
\hline 3 & $\begin{array}{l}\text { Banana boat menjadi wahana } \\
\text { yang cukup menarik di coba }\end{array}$ & 86 & Baik \\
\hline 4 & $\begin{array}{l}\text { Kano menjadi wahana yang } \\
\text { cukup menarik di coba }\end{array}$ & 85 & Baik \\
\hline 5 & $\begin{array}{l}\text { Parasailing menjadi wahana } \\
\text { yang cukup menarik di coba }\end{array}$ & 85 & Baik \\
\hline 6 & $\begin{array}{l}\text { Keramahan dan tanggung jawab } \\
\text { pengelola wisata Mirah Fantasia } \\
\text { membuat wisatawan ingin } \\
\text { berkunjung Kembali }\end{array}$ & 84 & Baik \\
\hline 7 & $\begin{array}{l}\text { Melibatkan pengunjung dalam } \\
\text { menjaga wahana pariwisata } \\
\text { olahraga }\end{array}$ & 87 & $85 \%$ \\
\hline & \multicolumn{1}{c}{ Total Rata-rata } & \\
\hline
\end{tabular}


Tabel 6.

Persepsi wisatawan tentang pengelolaan

\begin{tabular}{clcc}
\hline No & \multicolumn{1}{c}{ Sumber Informasi } & Persentase \% & Kategori \\
\hline 1 & $\begin{array}{l}\text { Tarik terjangkau membuat } \\
\text { wisatawan tertarik berkunjung ke } \\
\text { Mira Fantasia }\end{array}$ & 82 & Baik \\
\hline 2 & $\begin{array}{l}\text { Penyedian tong sampah sangat } \\
\text { membantu untuk menjaga } \\
\text { kebersihan lingkungan }\end{array}$ & 95 & Baik \\
\hline 3 & $\begin{array}{l}\text { Saya melihat kebersihan di } \\
\text { wahana olahraga Mirah Fantasia } \\
\text { terjaga dengan baik }\end{array}$ & 84 & Baik \\
\hline 4 & $\begin{array}{l}\text { Keamanan di Mirah Fantasia } \\
\text { sangat bagus }\end{array}$ & 83 & Baik \\
\hline 5 & $\begin{array}{l}\text { Saya mendukung pariwisata } \\
\text { olahraga di Mirah Fantasia } \\
\text { berjalan dengan lancar }\end{array}$ & 87 & Baik \\
\hline & \multicolumn{1}{c}{ Total Rata-rata } & $86 \%$ & \\
\hline
\end{tabular}

\section{PEMBAHASAN}

Berdasarkan hasil kuisioner yang disebarkan ke wisatawan yang berkunjung ke Mirah Fantasia memiliki rata-rata persentase baik dari 28 pernyataan, dapat dikatakan bahwa wisata Mirah Fanrtasia menjadi tempat rekreasi favorit keluarga. Pernyataan yang memiliki persentase tertimggi penyedian tong sampah sangat membantu untuk menjaga kebersihan lingkung memiliki persentase 95\% sedangkan untuk pernyataan persentase terkecil kamar mandii dalam mondisi bersih memiliki persentase $83 \%$. Untuk kedepan dengan adanya penelitian ini bisa mengetahui kekurangan dan kelebihan Mirah Fantasia sehingga bisa menjadi acuan untuk pengelola untuk mengembangkannya lagi.

\section{PENUTUP}

\section{Simpulan}

1. Wisatawan mendapatkan informasi secara cepat, menarik dan tertuju, baik menggunakan media pemasaran (media cetak, pamleet dan banner) maupun menggunakan media sosial (google, instagram, dan web resmi Mira Fantasia) yang bertujuan untuk mengenalkan potensi pariwisata olahraga dan rekreasi yang ada di Mira Fantasia. Tetapi diantara beberapa media yang digunakan untuk promosi media sosial yang sangat berpengaruh dalam menyampaikan informasi tentang potensi serta daya tarik pariwisata olahraga dan rekreasi yang ada di Mira Fantasia karena mudah diakses oleh wisatawan.

2. Persepsi wisatawan tentang pariwisata olahraga yang ada di Mira Fantasia cukup baik, dapat dilihat dari hasil penelitian yang rata-rata persentasenya cukup baik.

3. Kabupaten Banyuwangi memiliki luas wilayah $5.782 \mathrm{~km}$, yang di dalamnya terdapat banyak tempat wisata alam maupun pariwisata olahraga yang dikelolah secara baik salah satunya Mira Fantasia yang di dalamnya terdapat wahana pariwisata olahraga yang menjadi tempat favorit berkunjung dengan keluarga. Wisatawan memiliki pemahaman yang positif tentang Mira Fantasia ketika mengetahui hal tersebut mereka akan meningkatkan minat berkunjung di kabupaten Banyuwangi.

\section{Saran}

Berdasarkan simpulan penelitian tersebut, adapun saran yang dapat diberikan adalah sebagai berikut :

1. Bagi Wisatawan

Wisatawan atau pengunjung di harapkan tetap menjaga kebersihan tempat wisata 
yang di kunjungi dan juga menaati tata tertib yang telah ditetapkan oleh pengelolah agar tempat tersebut tetap bersih dan nyaman.

2. Bagi Peneliti

Bagi peneliti lain yang berminat untuk melakukan penelitian deskriptif persentase tentang persepsi wisatawan terhadap pariwisata olahraga di Mirah Fantasia, agar menjadikan penelitian ini sebagai referensi untuk meneliti dalam ruang lingkup yang lebih luas, sehingga diperoleh sumbangan ilmu yang lebih baik dan sesuai dengan perkembangan zaman dan diperoleh dalam penelitian lebih objektif.

3. Bagi Pengelolah

Pengelolah diharapkan agar terus berbenah dan memberbaiki setiap wahana pariwisata olahraga yang ada di wisata tersebut agar menarik minat wisatawan.

\section{Daftar Pustaka}

Bagus Rai, Gusti, and Made Eka Mahadewi. 2012 Metode Penelitian Pariwisata dan Perhotelan. Yogyakarta: CV Andi Offset.

Muljadi, Andri Warman. 2016. Kepariwisataan Dan Perjalanan. Jakarta: PT Raja Grafindo Persada.

Samehe, Januar Valentino, dan Paulus Kindagen. 2015. "International Tourist" Perception and Tourist Visitation To." 15(05): 514-27. https://ejournal.unsrat.ac.id/index.php/j bie/article/view/ 9874.

Utama, IGBR. 2018. Stastistik Penelitian Bisnis Dan Pariwisata. Yogyakarta: ANDI.

Widyasmara, Ida Bagus Made, I Made Kusuma Negara, and I Wayan Suardana. 2013. "Persepsi Wisatawan Terhadap Wisata Pantai Di Kelurahan Pecatu Kabupaten Badung Dalam Perencanaan Paket Wisata." Jurnal IPTA 1(1): 5. https://ojs.unud.ac.id/index.php/pariwis ata/article/view/26547. 